\title{
Mechanical and Structural Properties of Nanocarbon Particles Reinforced in Plasticised Polylactic Acid for High Strength Application
}

\author{
Ajidasile Segun, ${ }^{*}$ Benjamin Omotayo Adewuyi, ${ }^{1}$ Daramola Oluyemi Ojo, ${ }^{1}$ \\ and Olaiya Niyi Gideon ${ }^{2 *}$ \\ ${ }^{1}$ Department of Metallurgical and Material Engineering, \\ Federal University of Technology PMB 704, Akure, Nigeria \\ ${ }^{2}$ Department of Industrial and Production Engineering, \\ Federal University of Technology PMB 704, Akure, Nigeria
}

"Corresponding authors: ajidasileolusegun@gmail.com; ngolaiya@futa.edu.ng

Published online: 25 August 2021

To cite this article: Segun, A. et al. (2021). Mechanical and structural properties of nanocarbon particles reinforced in plasticised polylactic acid for high strength application. J. Phys. Sci., 32(2), 41-56. https://doi.org/10.21315/jps2021.32.2.4

To link to this article: https://doi.org/10.21315/jps2021.32.2.4

\begin{abstract}
High strength application of biopolymers requires good mechanical strength. The tensile properties of polylactic acid (PLA) are relatively low for major industrial applications such as packaging, biomedical and automobile spare parts. In this study, the mechanical strength of polylactic acid was enhanced with nanocarbon isolated from diesel engine combustion soot. The isolated nanocarbon was characterised using spectrometry and Fourier transform infrared (FTIR) spectroscopy analysis. After that, the nanocarbon was used as a reinforcement in plasticised PLA to produce a composite. The PLA-nanocarbon composite was produced using the compression moulding technique. The nanocarbon composition was varied between 2 wt $\%$ and $8 w t \%$ in the PLA matrix. The tensile, hardness and morphological properties of the composite were analysed with the tensile test, hardness test, optical microscope and X-ray diffraction (XRD) analysis. The ultraviolet (UV) spectrometer and FTIR analysis results confirmed the successful isolation of nanocarbon from the diesel engine combustion soot. The tensile and hardness properties of the PLA matrix increased with addition of nanocarbon. The morphological images showed good miscibility between the PLA and the nanocarbon reinforcement, responsible for the increase in mechanical properties. The potential use of the composite for high strength application showed great possibility based on the result obtained.
\end{abstract}

Keywords: polylactic acid, compression moulding, composite, nanoparticle 


\section{INTRODUCTION}

Synthetic polymers have been used for several applications, such as automobiles, packaging, and biomedical engineering. ${ }^{1-3}$ However, the global increase in plastic waste pollution has resulted in biodegradable polymers as an alternative for such an application. ${ }^{4}$ Biopolymers are also called biodegradable polymers and are isolated from natural sources (plants and animals). Biopolymers have been proposed as a replacement for synthetic polymers due to their biodegradability and biocompatibility. ${ }^{5}$ However, biopolymers generally have low mechanical strength, which reduced their suitability for industrial applications such as packaging, automobile interior and tissue repair. ${ }^{6-8}$ In a bid to solve this challenge, several methods, such as reinforcement, blending, etc., have been adapted to enhance the mechanical properties of biopolymers. ${ }^{8}$

Nanoparticles are used as fillers and nanofibres as reinforcement in biopolymers to enhance their mechanical strength. Carbon nanoparticle (CNP) and cellulose nanofibre have been used as fillers and reinforcement of biopolymers, respectively. CNPs used as fillers in biopolymers are produced majorly using mechanical, thermal or chemical treatment methods. ${ }^{9}$ The mechanical method of production of nanoparticles involved grinding the material with a ball mill machine. The thermal method deals with the combustion of organic material, which results in degradation, while the chemical method involved the chemical hydrolysis of the raw material with acid. ${ }^{9}$ Research on the reinforcement of commonly used biopolymers such as polylactic acid (PLA) and poly(butylene succinate) (PBS) has not been fully explored.

PLA is biodegradable, biocompatible and nontoxic biopolymer. ${ }^{10}$ PLA has been isolated from a carbohydrate source. ${ }^{11,12}$ Many researchers have studied PLA for potential application in packaging, biomedical and automobile interior parts. ${ }^{11,13,14}$ PLA based blend or reinforcement has been used for several biodegradable applications but not often for automobile parts because of its mechanical strength. ${ }^{15,16}$ The use of purely isolated CNP in PLA have been proposed for lightweight, a highperformance application such as in automotive industry. ${ }^{17}$ Several researchers have reviewed and studied PLA and carbon-based nanomaterials (CBN). ${ }^{15,18-20}$ However, the properties of plasticised PLA/CNPs composites have not been researched. ${ }^{21}$ In this study, CNP was isolated with a modified method and used as reinforcement in a plasticised PLA matrix. The miscibility of the polymer mix was enhanced with plasticiser and the morphological enhancement studied. 


\section{MATERIALS AND METHODS}

\subsection{Materials}

Carbon soot was isolated from diesel engine combustion and was further subjected to precipitation processes to isolate CNPs from the soot. The isolated nanoparticles were used in this research. Practical grade PLA (PLA4044D) was purchased from Sigma Aldrich (Lagos, Nigeria) with a tensile strength of $55 \mathrm{MPa}$, tensile modulus $3,500 \mathrm{MPa}$ and process temperature $200^{\circ} \mathrm{C}$ to $210^{\circ} \mathrm{C}$. Bis(2-Ethylhexyl) phthalate was also bought from Sigma Aldrich. Silicon oil was used for lubrication during the moulding and dioctyl phthalate (DOP) plasticiser was used as a compatibiliser for good fluidity of the mixture.

\subsection{Isolation of CNP}

CNP was isolated from a diesel engine's carbon soot with a modified method reported by Omoogun et al. ${ }^{22}$ The carbon soot was mixed with acetone and distilled water and stirred for $10 \mathrm{~min}$ at room temperature. The mixture was further centrifuged for an average of 4,000 rpm for $15 \mathrm{~min}$. The supernatant concentration was collected and dried at room temperature. The treated carbon soot was subjected to spectrometric analysis using Shimadzu UV 1289 ultraviolet-visible (UV-vis) spectrophotometer (Shimadzu manufacturing, Kyoto, Japan) at $250 \mathrm{~nm}$ to $800 \mathrm{~nm}$. The absorbance of the soot was obtained at a slit width of $0.5 \mathrm{~nm}$.

\subsection{Production of PLA/Nanocarbon Composite}

PLA was mixed with $2 \%, 4 \%, 6 \%$ and $8 \%$ of the isolated CNP. Bis(2-Ethylhexyl) phthalate $(5 \%)$ plasticisers were added to the prepared samples. ${ }^{23}$ The filled mould was placed in the Carver compression moulding machine (Carver Inc., Wabash, USA) at a temperature of $150^{\circ} \mathrm{C}$, at the pressure of $6 \mathrm{~Pa}$ for $20 \mathrm{~min}$. Samples were produced in five replicates for each composition in Table 1. The percentage variation of nanocarbon reinforcement was restricted between $2 \%$ and $8 \%$ based on previous studies. ${ }^{24,25}$ The moulded samples were kept in a zip lock bag for testing.

Table 1: Composition variation.

\begin{tabular}{ccc}
\hline S/N & Polylactic acid (wt \%) & Nanocarbon (wt\%) \\
\hline 1 & 98 & 2 \\
2 & 96 & 4 \\
3 & 94 & 6 \\
4 & 92 & 8 \\
5 & 100 & 0 \\
\hline
\end{tabular}




\subsection{Characterisation of the PLA-CNP}

The composite cast samples were cut to standard sizes for characterisation. The tensile test was done on dumbbell-shaped samples of standard dimension according to ASTM 3039. ${ }^{26}$ The moulded samples were tested with an Instron universal testing machine model 5966 (Instron, Norwood, MA, USA) at a machine load of $10 \mathrm{KN}$. The value of the tensile strength, tensile modulus and elongation were obtained. The hardness properties of the control (neat PLA) and the composites samples were measured with micro hardness tester LM700AT (Michigan, USA). The hardness value was obtained as the resistance to impression from the machine on the samples at a load of $490 \mathrm{~N}$ for $10 \mathrm{sec}$. The samples were tested for hardness with standard ISO 868. ${ }^{27}$ The morphology of the control sample and the PLA/CNP composites were observed with the aid of an optical OMAX microscope (S7M7045/SZM7045TR, Omax, Yeonggi-do, Korea) with a camera specification of 14 MP. The micrograph images were taken and studied. The X-ray diffraction (XRD) spectroscopy (crystal structures) of the PLA and the composite samples were studied with Shimadzu XDS $2400 \mathrm{H}$ diffractometer (Shimadzu manufacturing, Kyoto, Japan) with $\mathrm{Cu}$ anode, $\lambda \mathrm{CU}=1.5406\left[\mathrm{~A}^{\circ}\right]$, attached to the digitised computer. The diffraction beams monochromatic was operated at $40 \mathrm{KVA}$, a current of $30 \mathrm{~mA}$ with the $2 \theta$ range of $20^{\circ}$ to $95^{\circ}$ and a scan speed of $2 \%$ min with a step size of 0.02 for 120 min.

\section{RESULTS AND DISCUSSION}

\subsection{Characterisation Result of the Isolated CNPs}

\subsubsection{UV analysis of the particle size}

Figure 1 showed the result of the UV analysis of the raw carbon soot and the treated CNPs. Single absorption spectra of raw carbon soot were observed with a peak at $271 \mathrm{~nm}$. The treated CNPs showed three sets of peaks. A decline peak at $261 \mathrm{~nm}$, the highest peak at $297 \mathrm{~nm}$ and a lower peak at $330 \mathrm{~nm}$. Further increase in wavelength for the raw carbon soot and treated CNPs resulted in a decline in the absorption spectra till $600 \mathrm{~nm}$. The UV absorption analysis showed no significant emission with increasing wavelength after $600 \mathrm{~nm}$. The significance of this result showed improvement in the crystallinity index of the treated CNPs based on previous work of literature. ${ }^{28}$ The shift in the absorption peak was a result of the peak shift. The raw sample's peak absorbance, which is at $271 \mathrm{~nm}$, shows that the characteristic average particle size is at an approximate value of less than $10 \mathrm{~nm}$. A similar trend was reported in previous studies. ${ }^{29,30}$ 


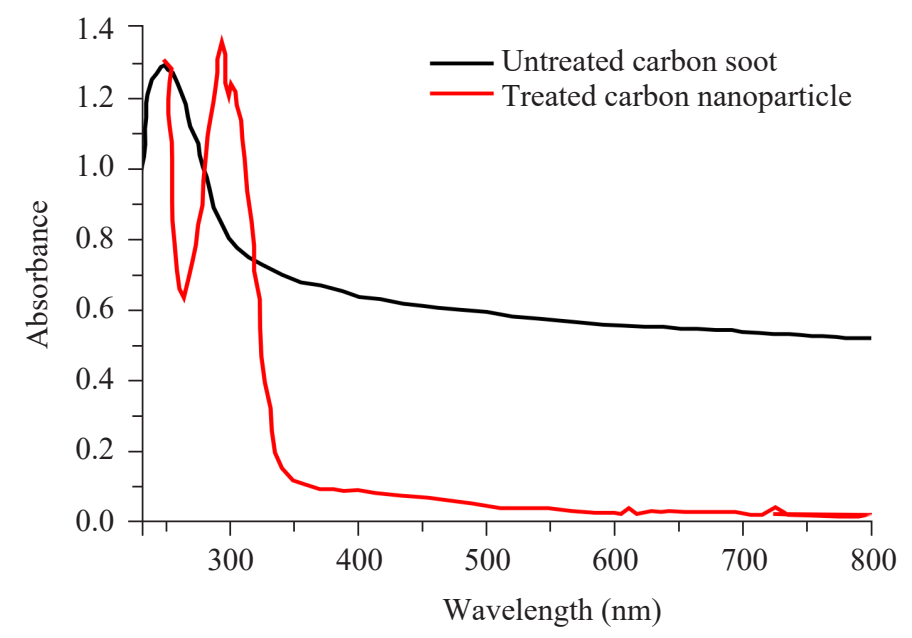

Figure 1: UV-vis spectrum of untreated carbon soot and treated CNP.

\subsubsection{FTIR analysis}

Figure 2 shows the result of the FTIR analysis of the treated CNP. The spectra indicated the presence of functional groups of hydrocarbons. The weak peak at $770.3 \mathrm{~nm}$ corresponds to the $\mathrm{O}-\mathrm{H}$ stretch, the peak at $328 \mathrm{~nm}$ showed $\mathrm{C}-\mathrm{H}$, and a very weak peak at $542 \mathrm{~nm}$ is characteristic of $\mathrm{C}=\mathrm{C}$ aromatic stretch. The $308.4 \mathrm{~nm}$ showed the $\mathrm{CH}$ stretching and $443 \mathrm{~nm}$ indicated $\mathrm{C}=\mathrm{C}\left(\mathrm{sp}^{2}\right)$ stretching modes. Furthermore, between 542.0 and $664.8 \mathrm{~nm}$ is the $\mathrm{CH}$ bending and $\mathrm{C}-\mathrm{C}\left(\mathrm{sp}^{3}\right)$ stretching. The $770.3 \mathrm{~nm}$ to $801.2 \mathrm{~nm}$ region represented the $\mathrm{CH}$ "out-of-plane" (wagging) bending motions. The band found in the $279.0 \mathrm{~nm}$ to $308.4 \mathrm{~nm}$ range showed the defect band. At $570 \mathrm{~nm}$ to $668 \mathrm{~nm}$, the band indicated aromatic $\mathrm{C}=\mathrm{C}$ stretching mode, and this band is attributed to $\mathrm{a}_{3}$ bending motion.

The characteristic bonds indicated in the FTIR analysis showed a typical bond present in a polyaromatic unit. ${ }^{30}$ The FTIR study still reveals the presence of a strong G-band with less disorder in the sample. Also, the peak at $542.0 \mathrm{~nm}$ is attributed to unburnt hydrocarbons, contamination and surface functionalities. The peak around $467.0 \mathrm{~nm}$ is attributed to the $\mathrm{C}-\mathrm{O}$ bond stretching. From the observed peaks, it is inferred that the sample contains carbon. The peak appearing between $417.0 \mathrm{~nm}$ and $542.0 \mathrm{~nm}$ is usually used in characterising a methyl group. The spectrum shows the detection of several absorption FTIR peaks, confirming chemical bonds in the sample. However, from this FTIR analysis result, amidst diamond-like carbon $\mathrm{sp}^{3}$, the sample contains allotrope graphite due to detection of peaks at $682.0\left(\mathrm{sp}^{3}-\mathrm{CH} 2-3\right.$ bend or $\mathrm{sp}^{2}$ aromatic $\mathrm{C}=\mathrm{C}$ stretching) and 734.8 ( $\mathrm{sp}^{2}$ aromatic) $\mathrm{CH}$ out plane bend. ${ }^{9}$ 


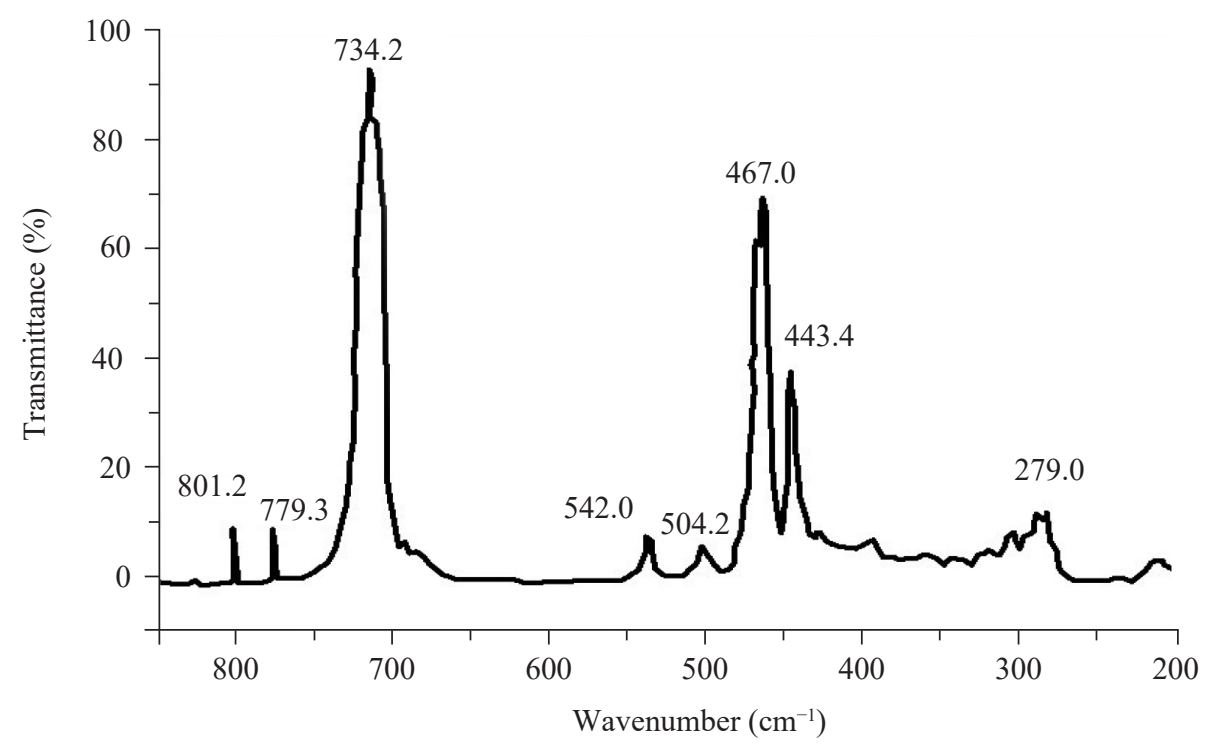

Figure 2: FTIR spectrum of CNPs.

\subsection{Tensile Properties}

The tensile strength for the control sample and the different weight percentage of the nanocarbon reinforced composites is shown in Figure 3. The strength of the PLA is significantly improved with the addition of CNP. The tensile strength of the composite is observed to increase with the increase in CNP. The highest strength was obtained with $8 \mathrm{wt} \%$ nanocarbon. Furthermore, the improved strength could also be attributed to good dispersion of the nanocarbon in the PLA matrix and formation of hydrogen bond according to Chiu et al. ${ }^{31}$ The result of Jamil et al. showed that further addition above a certain percentage reduced the tensile strength of PLA. ${ }^{32}$ This was probably due to a weak interfacial area between the particle and matrix increases.

The Young modulus of the PLA and PLA/nanocarbon composite is presented in Figure 4. The modulus value of the composite increased generally compared to the neat PLA. However, the composite modulus with $8 \% \mathrm{CNPs}$ resulted in a drop in the modulus. A percentage increase in the modulus up to $25 \%$ was observed compared to the neat PLA. The increase in the composite's modulus value could be attributed to the good dispersion of the nanocarbon in the PLA matrix. ${ }^{31,33}$ The reduction in modulus values of $8 \mathrm{wt} \%$ could result from more than enough nanocarbon filler in the matrix, which results in some of the CNPs not bonded to the PLA and result in increased stress in the atomic structure of the composite. ${ }^{34}$ 


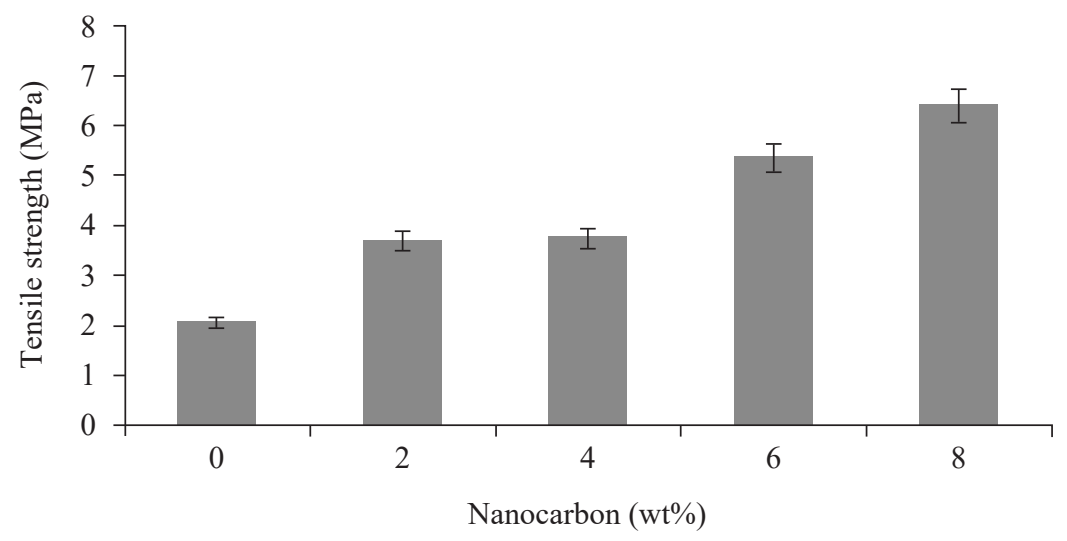

Figure 3: Tensile strength of neat PLA and plasticised PLA/nanocarbon composites.

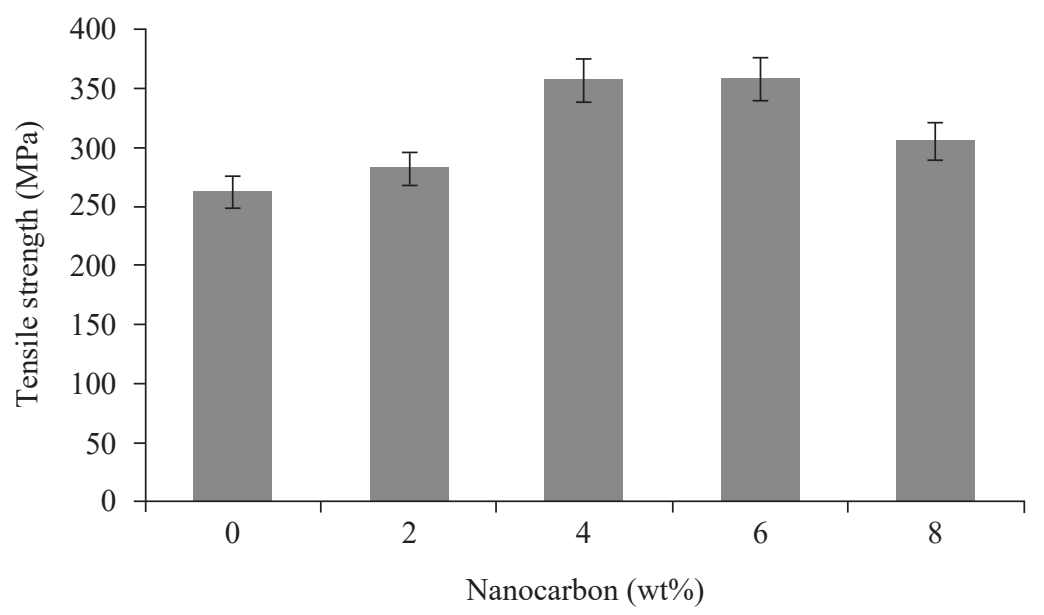

Figure 4: Tensile modulus of neat PLA and plasticised PLA/nanocarbon composites.

The elongation at break values depends on the filler/matrix interactions. Figure 5 presented the percentage elongation at break of the control sample and the PLA/nanocarbon composite. The result showed that the elongation of PLA was significantly improved. The elongation value improved from $25.4 \%$ for neat PLA to $96.2 \%$ at $6 \%$ addition of CNPs. Compared with the neat PLA, the elongation of the composites showed a significant increase of $53.1 \%, 43.9 \%, 73.6 \%$ and $56.4 \%$ for addition of $2 \%, 4 \%, 6 \%$ and $8 \%$, respectively. The increase in elongation is due to the transfer of load from PLA matrix to CNPs which climax at $6 \%$ of nanocarbon. The elongation reduced above $6 \%$, probably due to the agglomeration of filler in the matrix due to the high percentage. ${ }^{35}$ 


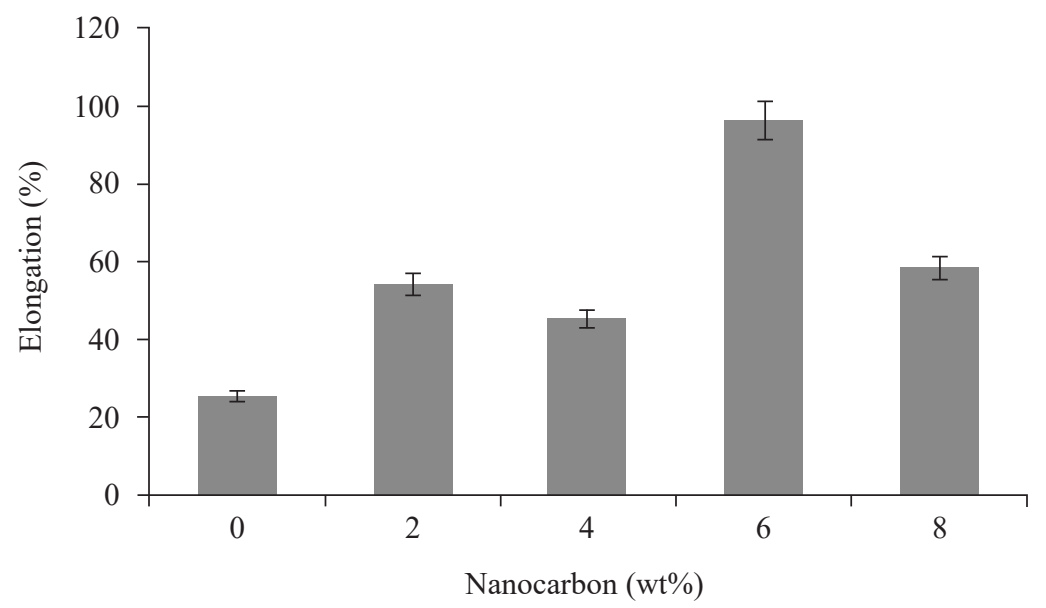

Figure 5: Percentage elongation of the neat PLA and plasticised PLA/nanocarbon composites.

\subsection{Hardness Properties}

Figure 6 shows the result of the hardness properties of the PLA and different loading of the PLA/nanocarbon. The hardness of the composite improved compared with the neat PLA. The hardness value improvement was observed due to good surface interaction between the matrix and the reinforcement enhanced by the plasticiser.$^{36}$ According to Raquez et al., it was observed that better dispersion of carbon nanotube (CNT) was achieved when carboxylic-functionalised CNT was used for the reinforcement of PLA, and this also resulted in improved mechanical properties. ${ }^{37}$ Furthermore, the nanocarbon used for the reinforcement was prepared by acetone which invariably enhanced the dispersion to an acceptable level, thereby improving the hardness values.

\subsection{Morphological Analysis}

The morphological features of the neat PLA and the developed composite was observed with the optical microscope, as shown in Figure 7. The optical microscope images were taken to observe the dispersion of CNPs in the plasticised PLA matrix. It could be observed that the micrograph of the control sample, as shown in Figure 7(a) and 7(b) is opaque, which could be attributed to the crystallinity. This crystallinity could be due to the high processing temperature used since PLA is a semi-crystalline polymer. ${ }^{38}$ For Figure $7(\mathrm{c})$ and $7(\mathrm{~d})$, it could be seen that the CNPs cause further nucleation in the matrix as tiny sizes of spherulites could be seen. 


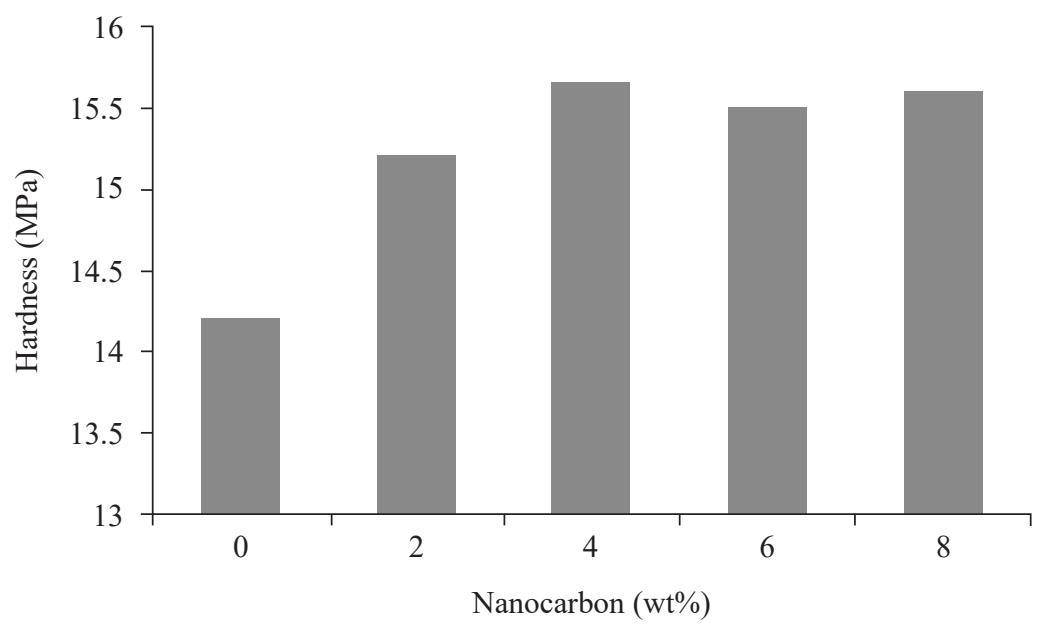

Figure 6: Hardness values of the neat PLA and plasticised PLA/nanocarbon composites.

Further increase in the nanocarbon quantity, as seen in Figure 7(e) and 7(f) causes more dispersion across the matrix, thereby enhancing the crystallinity. It could be observed that the surfaces of nanocarbon are a good nucleation site. By introducing it into the PLA, the matrix serves to improve the crystallisation of the PLA matrix, which agrees with study by Ramontja et al..$^{39}$ The optical micrograph of all the composite showed good dispersion, which is probably due to the plasticiser's addition. The micrograph's good dispersion resulted in significant improvement in the mechanical properties, as reported in Figure 3.

\subsection{XRD Analysis}

Figure 8 shows the XRD patterns of the neat PLA and various nanocarbonreinforced polymer composites' composition. The result of the XRD analysis showed several peaks. The composite with $2 \%$ nanocarbon has peaks of $26.52^{\circ}$, $41.82^{\circ}$ and $76.20^{\circ}$, which correspond to crystal plane (100), (200) and (220). Also, the composite with $4 \%$ nanocarbon has peaks of $26.71,42.61$ and 75.95 , which correspond to crystal planes (100), (121) and (220). The composite with $6 \%$ nanocarbon has peaks of $26.76,41.59$ and 75.95 , which correspond to crystal plane (100), (200) and (220). Finally, the composite with the $8 \%$ nanocarbon has peaks of (100), (121) and (220). There is no significant distortion to the spectra, which can also be seen in their d-values (the inter-planar distance). Each spectrum shows similar diffraction peaks, which shows that the nanocarbon did not cause any distortion to the structure of the PLA. ${ }^{40}$ 

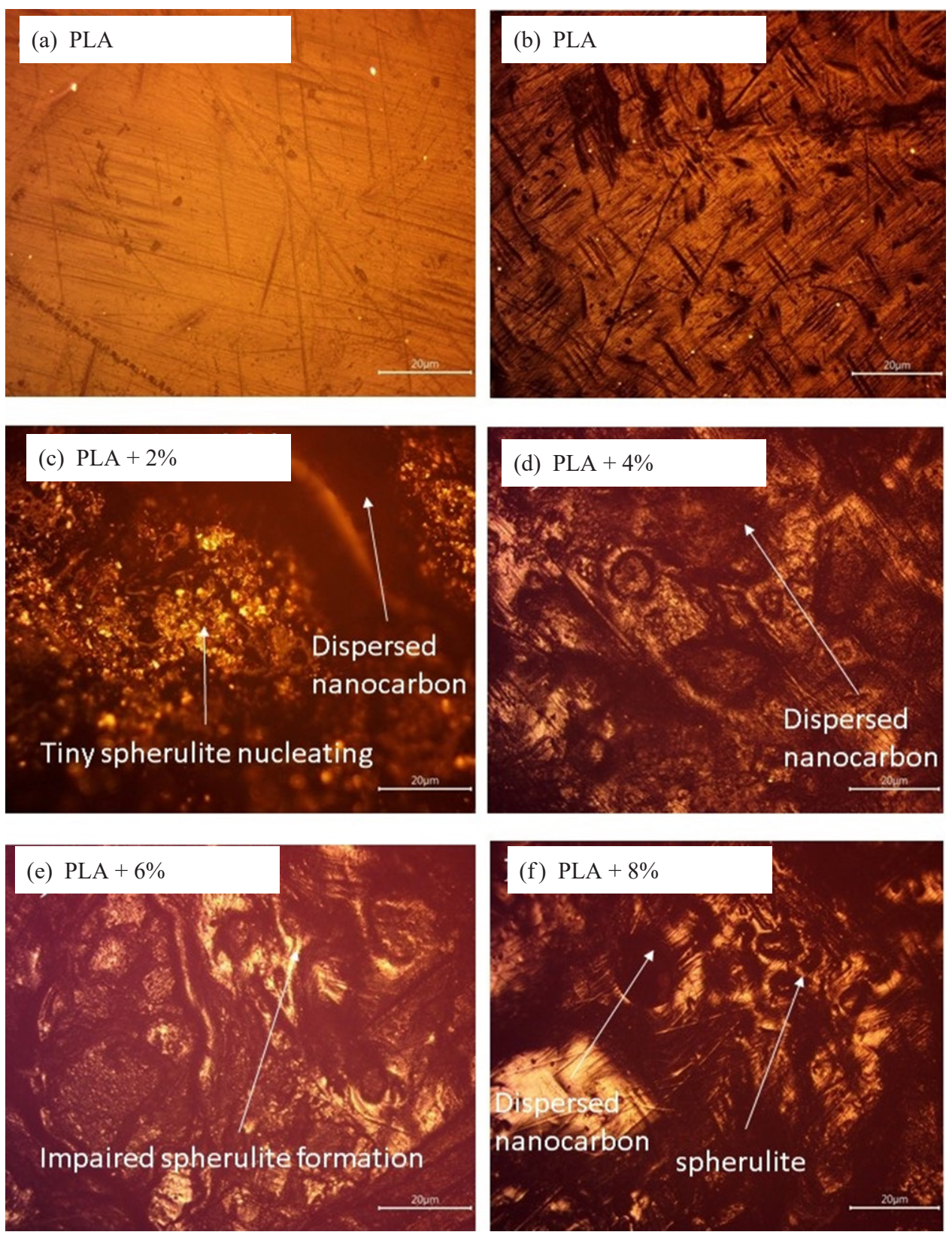

Figure 7: Optical micrograph of (a) neat PLA at 100×; (b) neat PLA; (c) PLA $+2 \%$; (d) PLA $+4 \%$; (e) PLA $+6 \%$; and (f) PLA $+8 \%$ composite. 

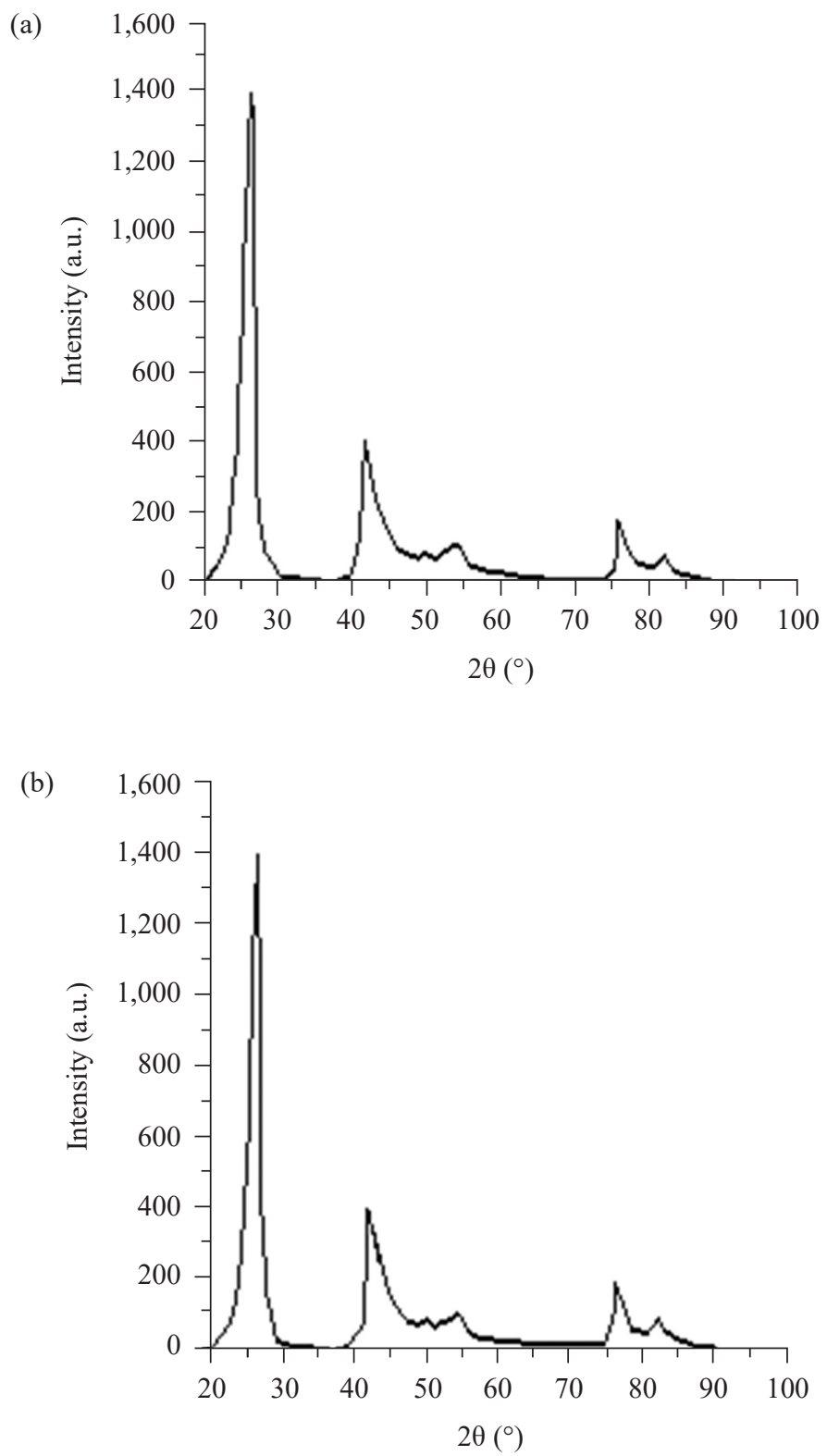

(Continued on next page)

Figure 8: XRD analysis of (a) neat PLA; (b) PLA/nanocarbon, $2 \mathrm{wt} \%$; (c) PLA/ nanocarbon, $4 \mathrm{wt} \%$; (d) PLA/nanocarbon, $6 \mathrm{wt} \%$ and (e) PLA/nanocarbon, $8 \mathrm{wt} \%$. 
(c)

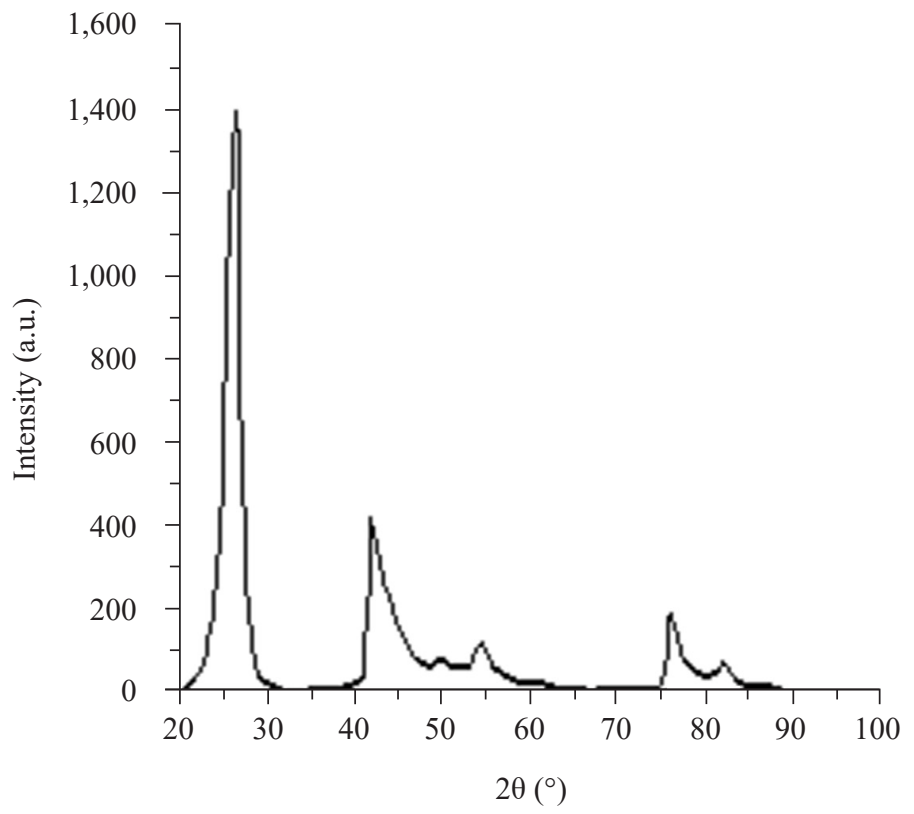

(d)

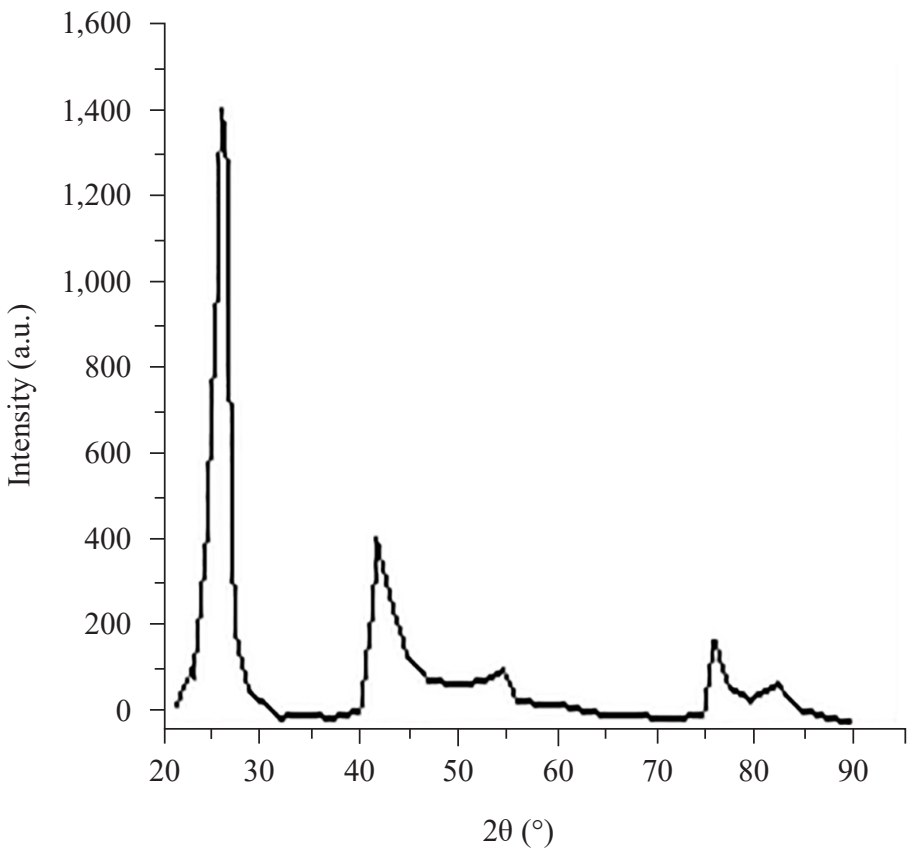

Figure 8: (Continued) 


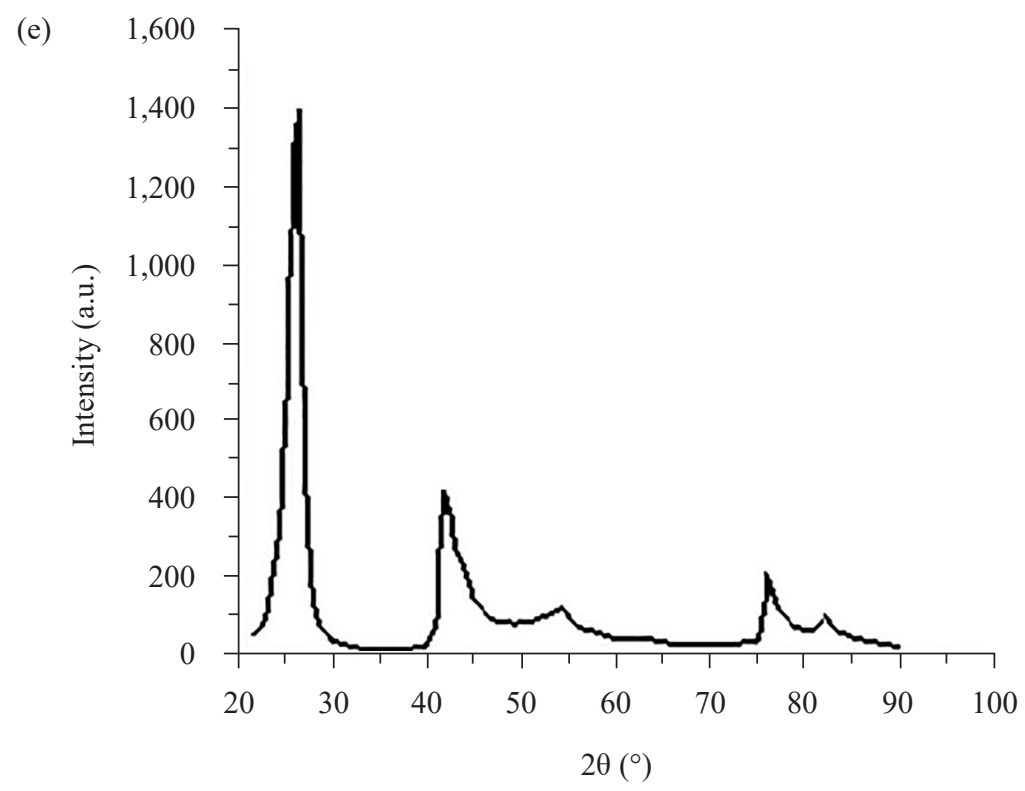

Figure 8: (Continued)

\section{CONCLUSION}

This present study confirms that nanocarbon can impart significant strength into the PLA matrix. The study reveals that the composite having $4 \mathrm{wt} \%$ nanocarbon recorded the highest young modulus. Also, the percentage elongation at break of all the composite developed is higher than the PLA. The elongation at break of the composites demonstrated an increase of $53.1 \%$ for $2 \mathrm{wt} \%, 43.9 \%$ increase in $4 \mathrm{wt} \%, 73.6 \%$ increase in $6 \mathrm{wt} \%$ and $56.4 \%$ increase for $8 \mathrm{wt} \%$. This developed composite's mechanical properties could be suitable for reinforcement as an implant for cancellous bone structures such as scaffold. Cancellous bone has low mechanical strength and they are found in areas where flexibility is required and are not subjected to high mechanical loading in the body.

\section{ACKNOWLEDGEMENTS}

The authors acknowledge the collaboration between the Federal University of Technology Akure and Tshwane University of Technology material test laboratory, making the project successful. 


\section{REFERENCES}

1. Alves, T. F. et al. (2020). Applications of natural, semi-synthetic, and synthetic polymers in cosmetic formulations. Cosmetics, 7(4), 75. https://doi.org/10.3390/ cosmetics 7040075

2. Muthuraj, R., Misra, M. \& Mohanty, A. K. (2018). Biodegradable compatibilized polymer blends for packaging applications: A literature review. J. Appl. Polym. Sci., 135(24), 45726. https://doi.org/10.1002/app.45726

3. Rodríguez-Rodríguez, R., et al. (2020). Composite hydrogels based on gelatin, chitosan and polyvinyl alcohol to biomedical applications: A review. Int. $J$. Polymc. Mater. \& Polymc. Biomater., 69(1), 1-20. https://doi.org/10.1080/0091 4037.2019.1581780

4. Borrelle, S. B., et al. (2020). Predicted growth in plastic waste exceeds efforts to mitigate plastic pollution. Science, 369(6510), 1515-1518. https://doi.org/10 $.1126 /$ science.aba3656

5. Siakeng, R., et al. (2019). Natural fiber reinforced polylactic acid composites: A review. Polym. Compos., 40(2), 446-463. https://doi.org/10.1002/pc.24747

6. Tang, X. et al. (2012). Recent advances in biopolymers and biopolymer-based nanocomposites for food packaging materials. Crit. Rev. Food Sci. Nutr., 52(5), 426-442. https://doi.org/10.1080/10408398.2010.500508

7. Murphy, C. A. \& Collins, M. N. (2018). Microcrystalline cellulose reinforced polylactic acid biocomposite filaments for 3D printing. Polym. Compos., 39(4), 1311-1320. https://doi.org/10.1002/pc.24069

8. Sadasivuni, K. K. et al. (2020). Recent advances in mechanical properties of biopolymer composites: A review. Polym. Compos., 41(1), 32-59. https://doi.org/ $10.1002 /$ pc. 25356

9. Singh, J. P. et al. (2018). Carbon nanoparticle synthesis, separation, characterization, and tribological property evaluation. Sep. Sci. Technol., 53(14), 2314-2326. https://doi.org/10.1080/01496395.2018.1446982

10. Karamanlioglu, M., Preziosi, R. \& Robson, G. D. (2017). Abiotic and biotic environmental degradation of the bioplastic polymer poly (lactic acid): A review. Polym. Degradation Stab., 137, 122-130. https://doi.org/10.1016/j .polymdegradstab.2017.01.009

11. Jamshidian, M. et al. (2010). Poly-lactic acid: Production, applications, nanocomposites, and release studies. CRFSFS, 9(5), 552-571. https://doi.org/10 $.1111 / \mathrm{j} .1541-4337.2010 .00126 . \mathrm{x}$

12. Sin, L. T. (2012). Polylactic acid: PLA biopolymer technology and applications. Norwich, NY: William Andrew. https://doi.org/10.1007/s00726-011-0885-3

13. Backes, E. H. et al. (2020). Fabrication of biocompatible composites of poly(lactic acid)/hydroxyapatite envisioning medical applications. Polym. Eng. Sci., 60(3), 636-644. https://doi.org/10.1002/pen.25322

14. Graupner, N., Herrmann, A. S. \& Müssig, J. (2009). Natural and man-made cellulose fibre-reinforced poly(lactic acid) (PLA) composites: An overview about mechanical characteristics and application areas. Compos. Part A Appl. Sci. Manuf., 40(6-7), 810-821. https://doi.org/10.1016/j.compositesa.2009.04.003 
15. Lasprilla, A. J. et al. (2012). Poly-lactic acid synthesis for application in biomedical devices: A review. Biotechnol. Adv., 30(1), 321-328. https://doi.org/ 10.1016/j.biotechadv.2011.06.019

16. Mamat, N., Jaafar, M. \& Hamid, Z. A. A. (2019). Surface modification of gentamicin-loaded polylactic acid (PLA) microsphere using double emulsion and solvent evaporation: Effect on protein adsorption and drug release behaviour. J. Phys. Sci., 30 (Supp. 1), 109-124. https://doi.org/10.21315/jps2019.30.s1.7

17. Volpe, V. et al. (2019). Lightweight high-performance polymer composite for automotive applications. Polymers, 11(2), 326. https://doi.org/10.3390/ polym 11020326

18. Allen, M. J., Tung, V. C. \& Kaner, R. B. (2010). Honeycomb carbon: A review of graphene. Chem Rev, 110(1), 132-145. https://doi.org/10.1021/cr900070d

19. Balandin, A. A. (2011). Thermal properties of graphene and nanostructured carbon materials. Nat. Mater., 10(8), 569-581. https://doi.org/10.1038/nmat3064

20. Gupta, B., Revagade, N. \& Hilborn, J. (2007). Poly(lactic acid) fiber: An overview. Prog. Polym. Sci., 32(4), 455-482. https://doi.org/10.1016/j. progpolymsci.2007.01.005

21. Zaaba, N. F. \& Ismail, H. (2019). Thermoplastic/natural filler composites: A short review. J. Phys. Sci, 30, 81-99. https://doi.org/10.21315/jps2019.30.s1.5.

22. Omoogun, A. et al. (2015). Luminescence carbon nanoparticles from soot. Nigeria: University of Lagos. https://ir.unilag.edu.ng/handle/123456789/4753

23. Greco, A. \& Maffezzoli, A. (2016). Cardanol derivatives as innovative bioplasticizers for poly-(lactic acid). Polym. Degrad. Stab., 132, 213-219. https://doi.org/10.1016/j.polymdegradstab.2016.02.020

24. Bourbigot, S. et al. (2011). Reactive extrusion of PLA and of PLA/carbon nanotubes nanocomposite: Processing, characterization and flame retardancy. Polym. Adv. Technol., 22(1), 30-37. https://doi.org/10.1002/pat.1715

25. Zhou, Y. et al. (2018). Preparation and characterization of polylactic acid (PLA) carbon nanotube nanocomposites. Polym. Test, 68, 34-38. https://doi.org/10 .1016/j.polymertesting.2018.03.044

26. ASTM D3039 / D3039M-17. (2017). Standard test method for tensile properties of polymer matrix composite materials. 2008, West Conshohocken, PA: ASTM International.

27. ISO. (2003). ISO 868:2003, Plastics and ebonite-determination of indentation hardness by means of a durometer (shore hardness). Geneva, Switzerland: ISO.

28. Tarasenka, N. et al. (2017). Structure and optical properties of carbon nanoparticles generated by laser treatment of graphite in liquids. Chem. Phys. Chem., 18(9), 1074-1083. https://doi.org/10.1002/cphc.201601182

29. Larosa, C. et al. (2017). Preparation and characterization of polycarbonate/ multiwalled carbon nanotube nanocomposites. Beilstein. J. Nanotechnol., 8(1), 2026-2031. https://doi.org/10.3762/bjnano.8.203

30. Bacakova, L. et al. (2020). Applications of nanocellulose/nanocarbon composites: Focus on biotechnology and medicine. Nanomaterials, 10(2), 196. https://doi .org/10.3390/nano10020196 
31. Chiu, W. M. et al. (2008). A study of carbon nanotubes/biodegradable plastic polylactic acid composites. J. Appl. Polym. Sci., 108(5), 3024-3030. https://doi .org/10.1002/app. 27796

32. Jamil, M. S., Ahmad, I. \& Abdullah, I. (2006). Effects of rice husk filler on the mechanical and thermal properties of liquid natural rubber compatibilized highdensity polyethylene/natural rubber blends. J. Polym. Res., 13(4), 315-321. https://doi.org/10.1007/s10965-005-9040-8

33. Wang, Y. et al. (2019). Improved fracture toughness and ductility of PLA composites by incorporating a small amount of surface-modified helical carbon nanotubes. Compos. B. Eng., 162, 54-61. https://doi.org/10.1016/j.compositesb .2019 .05 .067

34. Bafekrpour, E. et al. (2014). Effects of micro-structural parameters on mechanical properties of carbon nanotube polymer nanocomposites. Sci Iranica, 21(2), 403413.

35. Pinto, A. M., Magalhães, F. D. \& Gonçalves, I. C. (2016). Polymer surface adsorption as a strategy to improve the biocompatibility of graphene nanoplatelets. Colloids Surf. B: Biointerfaces, 146, 818-824. https://doi.org/10.1016/j.colsurfb .2016 .07 .031

36. Callister Jr, W. D. \& Rethwisch, D. G. (2018). Fundamentals of materials science and engineering: An integrated approach. UK: John Wiley \& Sons.

37. Raquez, J.-M. et al. (2013). Polylactide (PLA)-based nanocomposites. Prog. Polym. Sci., 38(10-11), 1504-1542. https://doi.org/10.1016/j.progpolymsci.2013 .05 .014

38. Ashok, B. et al. (2014). Tensile and thermal properties of poly (lactic acid)/ eggshell powder composite films. Int. J. Polym. Anal. Charact., 19(3), 245-255. https://doi.org/10.1080/1023666X.2014.879633

39. Ramontja, J. et al. (2009). High-performance carbon nanotube-reinforced bioplastic. Macromol. Mater. Eng., 294(12), 839-846. https://doi.org/10.1002/ mame.200900197

40. Zeng, J.-B., Li, K.-A., \& Du, A.-K. (2015). Compatibilization strategies in poly(lactic acid)-based blends. RSC Advances, 5(41), 32546-32565. https://doi .org/10.1039/C5RA01655J 